UCRL-JC-123410

PREPRINT

conf- $960252--5$

\title{
Flue Gas Dry Scrubbing Using Pulsed Electron Beams
}

\author{
B. M. Penetrante \\ Lawrence Livermore National Laboratory \\ Livermore, CA
}

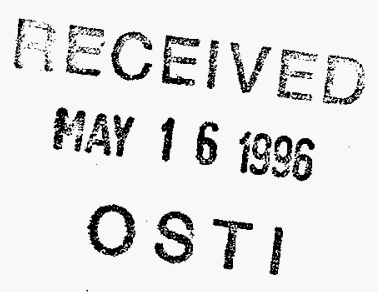

This paper was prepared for submittal to:

Second International Symposium on

Environmental Applications of Advanced Oxidation Technologies

San Francisco, CA

February 28 - March 1, 1996

February 20, 1996

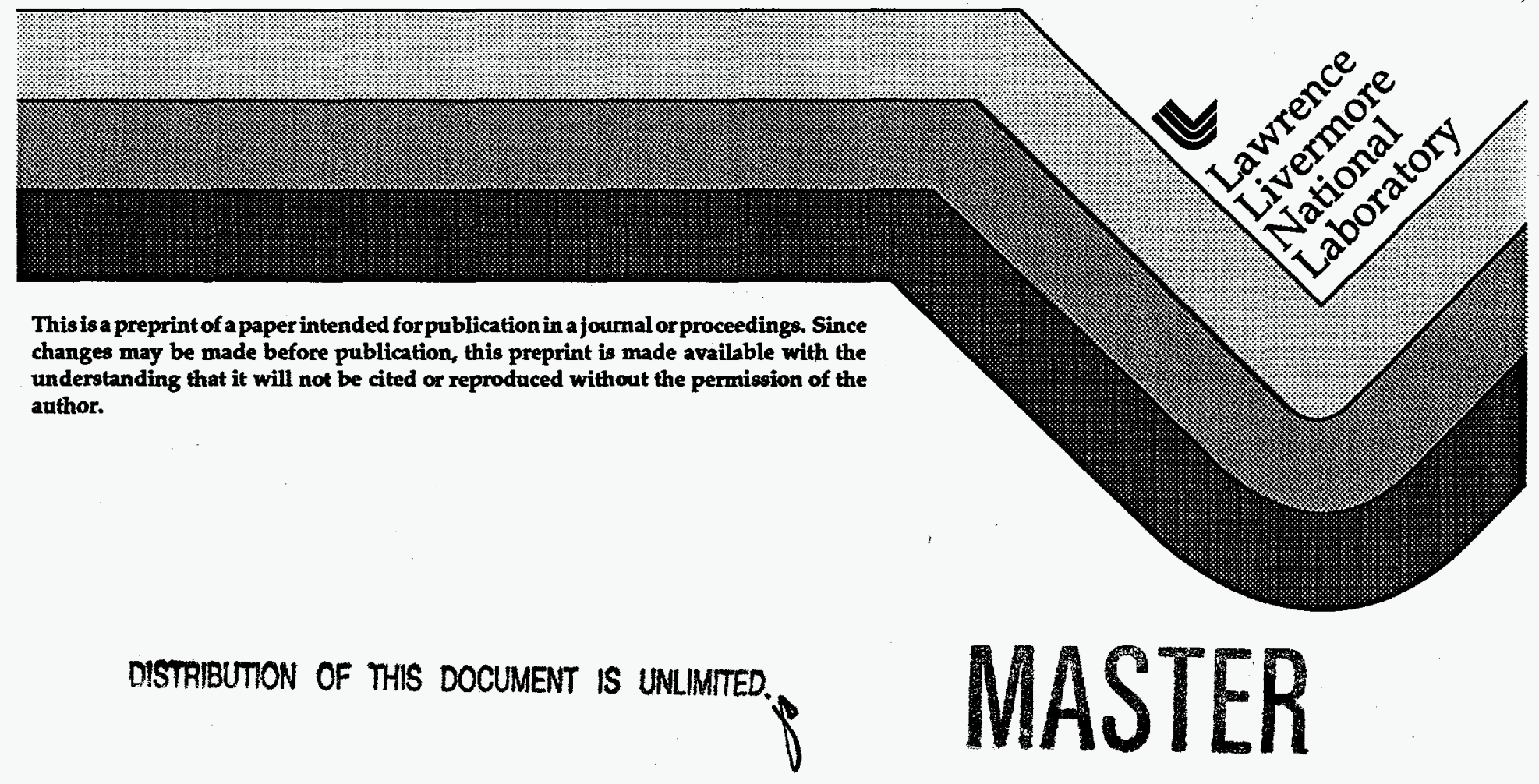




\section{DISCLAIMER}

This document was prepared as an account of work sponsored by an agency of the United States Government. Neither the United States Government nor the University of California nor any of their employees, makes any warranty, express or implied, or assumes any legal liability or responsibility for the accuracy, completeness, or usefulness of any information, apparatus, product, or process disclosed, or represents that its use would not infringe privately owned rights. Reference herein to any specific commercial product, process, or service by trade name, trademark, manufacturex, or other wise, does not necessarily constitute or imply its endorsement, recommendation, or favoring by the United States Government or the University of California. The views and opinions of authors expressed herein do' not necessarily state or reflect those of the United States Government or the University of California, and shall not be used for advertising or product endorsement purposes. 
Second International Symposium on

Environmental Applications of Advanced Oxidation Technologies

San Francisco, February 28 - March 1, 1996

\title{
FLUE GAS DRY SCRUBBING USING PULSED ELECTRON BEAMS
}

\author{
B. M. Penetrante \\ Lawrence Livermore National Laboratory \\ Livermore, California 94550
}

\begin{abstract}
Electron beam dry scrubbing is a technique for removing in a single step both nitrogen oxides $\left(\mathrm{NO}_{x}\right)$ and sulfur dioxide $\left(\mathrm{SO}_{2}\right)$ from the off-gas generated by utilities burning high sulfur coal. The use of pulsed electron beams may provide the most cost-effective solution to the implementation of this technique. This paper presents the results of plasma chemistry calculations to study the effect of dose rate, pulse length and pulse repetition rate on pulsed electron beam processing of $\mathrm{NO}_{\mathrm{x}}$ and $\mathrm{SO}_{2}$ in flue gases. The main objective is to determine if the proposed combinations of dose rate, pulse length and pulse repetition rate would have any deleterious effect on the utilization of radicals for pollutant removal. For a dose rate of $2 \times 10^{5}$ megarads per second and a pulse length of $\mathbf{3 0}$ nanoseconds, the average dose per pulse is sufficiently low to prevent any deleterious effect on process efficiency because of radical-radical recombination reactions. During each post-pulse period, the radicals are utilized in the oxidation of $\mathrm{NO}_{\mathbf{x}}$ and $\mathrm{SO}_{2}$ in a timescale of around 200 microseconds; thus, with pulse frequencies of around 5 kilohertz or less, the radical concentrations remain sufficiently low to prevent any significant competition between radical-pollutant and radical-radical reactions. The main conclusion is that a pulsed electron beam reactor, operating with a dose rate of $2 \times 10^{5}$ megarad per second, pulse length of $30 \mathrm{~ns}$ and pulse repetition rate of up to around 5 $\mathrm{kHz}$, will have the same plasma chemistry efficiency as an electron beam reactor operating with a very low dose rate in continuous mode.
\end{abstract}

\section{INTRODUCTION}

Electron beam dry scrubbing is a technique for removing in a single step both $\mathrm{SO}_{2}$ and $\mathrm{NO}_{x}$ from the off-gas generated by utilities burning high sulfur coal. The use of pulsed electron beams may provide the most cost-effective solution to the implementation of this technique. This paper studies the plasma-chemical kinetics of electron beam assisted removal of $\mathrm{SO}_{2}$ and $\mathrm{NO}_{\mathbf{x}}$ in flue gas streams under pulsed conditions. The main objective is to determine if the proposed combinations of dose rate, pulse length and pulse repetition rate would have any deleterious effect on the utilization of radicals for pollutant removal. 


\section{RESULTS AND DISCUSSION}

The $\mathrm{OH}$ radical plays the key role in the simultaneous removal of $\mathrm{NO}_{\mathbf{x}}$ and $\mathrm{SO}_{2}$. The important primary radical-pollutant reactions that consume $\mathrm{OH}$ radicals are:

$$
\mathrm{OH}+\mathrm{SO}_{2}+\mathrm{M} \rightarrow \mathrm{HSO}_{3}+\mathrm{M}
$$

followed by the production of the strongly oxidizing radical $\mathrm{HO}_{2}$ :

$$
\mathrm{HSO}_{3}+\mathrm{O}_{2} \rightarrow \mathrm{HO}_{2}+\mathrm{SO}_{3}
$$

Reaction (2) also induces the formation of sulfuric acid products:

$$
\mathrm{SO}_{3}+\mathrm{H}_{2} \mathrm{O} \rightarrow \mathrm{H}_{2} \mathrm{SO}_{4} \text {. }
$$

The $\mathrm{OH}$ radical is regenerated while simultaneously oxidizing NO:

$$
\mathrm{HO}_{2}+\mathrm{NO} \rightarrow \mathrm{NO}_{2}+\mathrm{OH}
$$

This sequence of reactions simultaneously oxidize $\mathrm{NO}$ and $\mathrm{SO}_{2}$ while regenerating the $\mathrm{OH}$ radical. This is the reason why this technique is particularly efficient for offgases generated by utilities burning high sulfur coal. Another $\mathrm{OH}$ radical could induce the formation of nitric acid products:

$$
\mathrm{OH}+\mathrm{NO}_{2}+\mathrm{M} \rightarrow \mathrm{HNO}_{3}+\mathrm{M}
$$

Under high dose rate conditions, it is possible that radical-radical reactions may occur that would consume the $\mathrm{OH}$ radicals and/or produce NO. One reaction could consume $\mathrm{OH}$ and produce NO:

$$
\mathrm{N}+\mathrm{OH} \rightarrow \mathrm{NO}+\mathrm{H}
$$

Another reaction depletes the two important oxidizing radicals $\mathrm{OH}$ and $\mathrm{HO}_{2}$ :

$$
\mathrm{OH}+\mathrm{HO}_{2}+\mathrm{M} \rightarrow \mathrm{H}_{2} \mathrm{O}+\mathrm{O}_{2}+\mathrm{M}
$$

There is a reaction that depletes $\mathrm{HO}_{2}$, gives back $\mathrm{OH}$, but produces NO:

$$
\mathrm{N}+\mathrm{HO}_{2} \rightarrow \mathrm{NO}+\mathrm{OH}
$$

And then there is a reaction that depletes two $\mathrm{OH}$ radicals and gives back only one of the less effective oxidizing radical $\mathrm{O}$ :

$$
\mathrm{OH}+\mathrm{OH} \rightarrow \mathrm{H}_{2} \mathrm{O}+\mathrm{O}
$$

Table I shows the effective two-body rate constants (in units of $\mathrm{cm}^{3}$ per molecule-second) for some of the more important radical-pollutant and radicalradical reactions. It is clear from the rate constant values that if the concentration of radicals is too high relative to the concentration of the pollutant molecules, then loss of radicals via radical-radical recombination would become deleterious to the efficiency of the process. Such a condition could exist if the rate of production of radicals is high because of excessive electron beam dose rates.

In addition to the rate constants, one needs to know the concentrations of the radicals in order to determine their rate of loss or utilization. The radical production rates are determined by a set of electron-impact reactions representing the excitation, dissociation and ionization of the background gas molecules by the electron beam. The initial gas concentrations used in the calculations consisted of $200 \mathrm{ppm}$ NO, 50 ppm $\mathrm{NO}_{2}, 3000$ ppm SO $2,3250 \mathrm{ppm} \mathrm{NH}_{3}, 5 \% \mathrm{O}_{2}, 10 \% \mathrm{CO}_{2}, 15 \% \mathrm{H}_{2} \mathrm{O}$ and balance $\mathrm{N}_{2}$. 
The calculations followed the evolution of 89 species. In addition to the 24 electronimpact reactions, there are 1129 reactions included in the plasma chemistry calculations. The electron beam parameters used in the calculations are shown in Table II.

The average dose per pulse is the important parameter that determines the maximum concentration of radicals produced during each pulse. As shown in Table II, the average dose is only 6000 rads per pulse. Note that the length of each pulse is much shorter compared to the time interval between pulses. Whether the radicals are completely utilized between pulses is determined by the pulse repetition rate.

Table I. Effective two-body rate constants at atmospheric pressure for some radicalpollutant and radical-radical reactions.

\begin{tabular}{|c|c|}
\hline Reaction & Elfective-2 Body Rate Constan $(\mathrm{cm} / \mathrm{s}$ ) \\
\hline $\mathrm{SO}_{2}+\mathrm{OH}+\mathrm{M} \rightarrow \mathrm{HSO}_{3}+\mathrm{M}$ & $7.8 \times 10^{-13}$ \\
\hline $\mathrm{NO}+\mathrm{HO}_{2} \rightarrow \mathrm{NO}_{2}+\mathrm{OH}$ & $7.5 \times 10^{-12}$ \\
\hline $\mathrm{NO}_{2}+\mathrm{OH}+\mathrm{M} \rightarrow \mathrm{HNO}_{3}+\mathrm{M}$ & $3.5 \times 10^{-11}$ \\
\hline $\mathrm{N}+\mathrm{OH} \rightarrow \mathrm{NO}+\mathrm{H}$ & $5.8 \times 10^{-11}$ \\
\hline $\mathrm{N}+\mathrm{HO}_{2} \rightarrow \mathrm{NO}+\mathrm{OH}$ & $2.2 \times 10^{-11}$ \\
\hline $\mathrm{OH}+\mathrm{OH} \rightarrow \mathrm{H}_{2} \mathrm{O}+\mathrm{O}$ & $1.0 \times 10^{-11}$ \\
\hline $\mathrm{OH}+\mathrm{HO}_{2}+\mathrm{M} \rightarrow \mathrm{H}_{2} \mathrm{O}+\mathrm{O}_{2}+\mathrm{M}$ & $1.0 \times 10^{-10}$ \\
\hline
\end{tabular}

Table II. Pulsed electron beam parameters used in the plasma chemistry calculations.

\begin{tabular}{|c|c|c|}
\hline Prapanineter: & Condition 1 & Condition 2 \\
\hline Dose Rate (Mrad/s) & $2 \times 10^{3}$ & $2 \times 10^{5}$ \\
\hline Pulse Length (ns) & 3000 & 30 \\
\hline Frequency $(\mathrm{Hz})$ & 67 & 6667 \\
\hline Average Dose per Pulse (rad) & 6000 & 6000 \\
\hline Gas Temperature $\left({ }^{\circ} \mathrm{C}\right)$ & 70 & 70 \\
\hline
\end{tabular}

The maximum concentration of radicals formed per pulse during electron beam irradiation with an average dose of $6000 \mathrm{rad}$ per pulse is shown in Table III. Note that the maximum concentration per pulse is around, or less than, $1 \mathrm{ppm}$. The rate constants, pollutant concentrations, and radical concentrations can be used together to get a rough estimate of the radical utilization and destruction rates for radical-pollutant and radical-radical reactions. These radical utilization and destruction rates are shown in Table IV. Note that the rates for radical-pollutant reactions are much greater than the rates for radical-radical recombination reactions. 
Table III. Maximum concentration of radicals formed per pulse during electron beam irradiation with an average dose of $6000 \mathrm{rad}$ per pulse.

\begin{tabular}{|c|c|}
\hline Radicall & Maximun concentration Formed (pprin) \\
\hline $\mathrm{OH}$ & 1.2 \\
\hline $\mathrm{HO}_{2}$ & 1.0 \\
\hline$N\left({ }^{4} S\right)$ & 0.25 \\
\hline $\left.\mathrm{O}^{3} \mathrm{P}\right)$ & 0.35 \\
\hline $\mathrm{O}_{3}$ & 0.12 \\
\hline
\end{tabular}

Table IV. Radical utilization and destruction rates for some radical-pollutant and radical-radical reactions.

\begin{tabular}{|c|c|}
\hline & \\
\hline $\mathrm{SO}_{2}+\mathrm{OH}+\mathrm{M} \rightarrow \mathrm{HSO}_{3}+\mathrm{M}$ & 55000 \\
\hline $\mathrm{NO}+\mathrm{HO}_{2} \rightarrow \mathrm{NO}_{2}+\mathrm{OH}$ & 30000 \\
\hline $\mathrm{NO}_{2}+\mathrm{OH}+\mathrm{M} \rightarrow \mathrm{HNO}_{3}+\mathrm{M}$ & 42000 \\
\hline $\mathrm{N}+\mathrm{OH} \rightarrow \mathrm{NO}+\mathrm{H}$ & 350 \\
\hline $\mathrm{N}+\mathrm{HO}+\mathrm{NO}+\mathrm{OH}$ & 111 \\
\hline $\mathrm{OH}+\mathrm{OH} \rightarrow \mathrm{H}_{2} \mathrm{O}+\mathrm{O}$ & 290 \\
\hline $\mathrm{OH}+\mathrm{HO}_{2}+\mathrm{M} \rightarrow \mathrm{H}_{2} \mathrm{O}+\mathrm{O}_{2}+\mathrm{M}$ & 2400 \\
\hline
\end{tabular}

The evolution of the concentration of radicals during a single pulse is shown in Figure 1. Note that the most important oxidizing radicals, $\mathrm{OH}$ and $\mathrm{HO}_{2}$, are consumed by radical-pollutant reactions in 200 microseconds or less. Thus, for pulse repetition rates of up to around $5 \mathrm{kHz}$, the concentration of these radicals remain sufficiently low to prevent any significant loss due to radical-radical recombination reactions.

Figure 2 shows the evolution of the concentration of NO. The NO concentration reaches a quasi-steady-state value before each next pulse. The amount of NO oxidation after each pulse is approximately the same for a dose rate of $2 \times 10^{5}$ $\mathrm{Mrad} / \mathrm{s}$, pulse length of $30 \mathrm{~ns}$, repetition rate of $6667 \mathrm{~Hz}$, and a dose rate of $2 \times 10^{3}$ $\mathrm{Mrad} / \mathrm{s}$, pulse length of $3000 \mathrm{~ns}$ and repetition rate of $67 \mathrm{~Hz}$. The oxidizing radicals are utilized effectively in both cases. For the case of $2 \times 10^{5} \mathrm{Mrad} / \mathrm{s}, 30 \mathrm{~ns}$ pulse, and $6667 \mathrm{~Hz}$ rep-rate, a small degradation in removal efficiency is evident after many pulses because the oxidation process is not completely finished before each next pulse. This degradation however is small and can be prevented completely by reducing the pulse repetition rate to $5 \mathrm{kHz}$ or less. 


\section{CONCLUSIONS}

The main conclusion of this study is that a pulsed electron beam reactor, operating with a dose rate of $2 \times 10^{5} \mathrm{Mrad} / \mathrm{s}$, pulse length of $30 \mathrm{~ns}$ and pulse repetition rate of up to around $5 \mathrm{kHz}$, will have the same efficiency for the simultaneous removal of $\mathrm{NO}_{x}$ and $\mathrm{SO}_{2}$ as an electron beam reactor operating with a very low dose rate in continuous mode.

\section{ACKNOWLEDGMENT}

This work was performed at Lawrence Livermore National Laboratory under the auspices of the U.S. Department of Energy under Contract Number W-7405ENG-48, with support from the DP Small Business Technical Assistance Program.
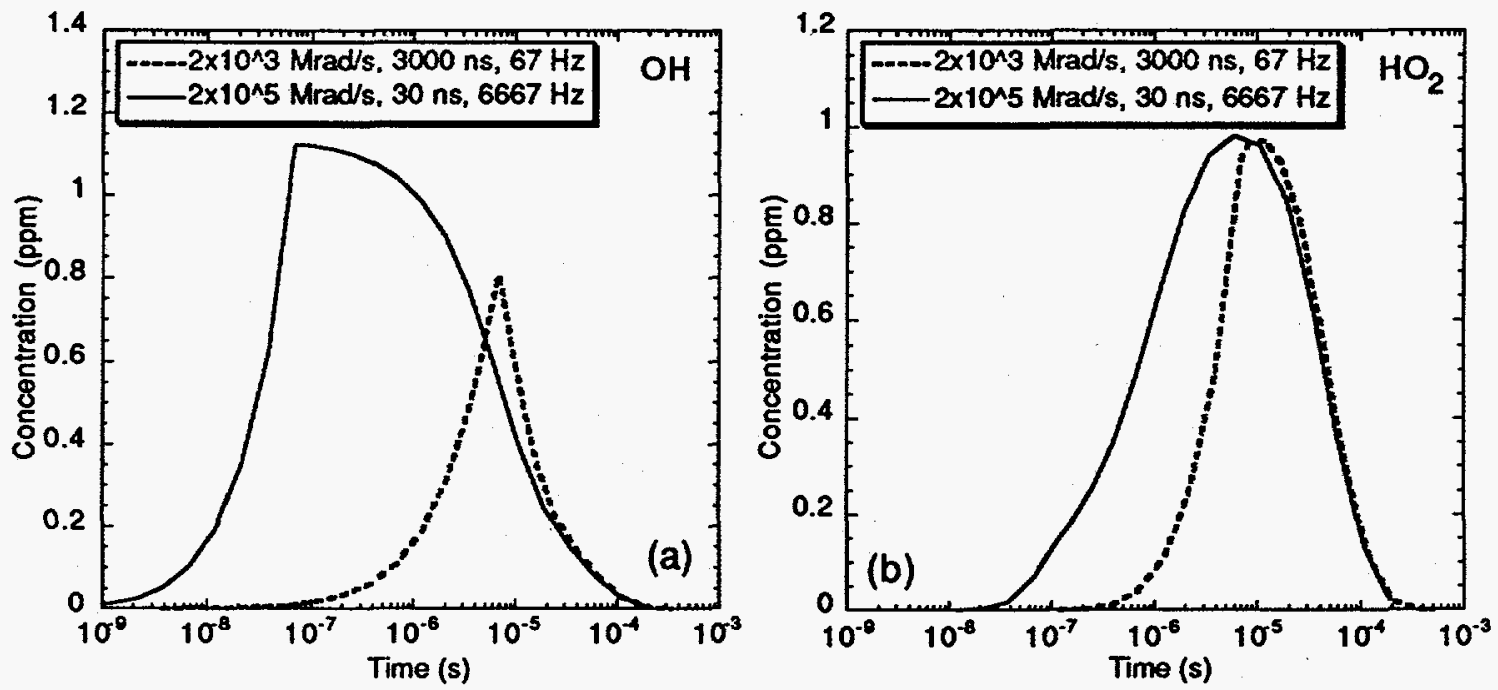

Figure 1. Evolution of the concentration of $\mathrm{OH}$ and $\mathrm{HO}_{2}$ radicals during a single pulse of electron beam.
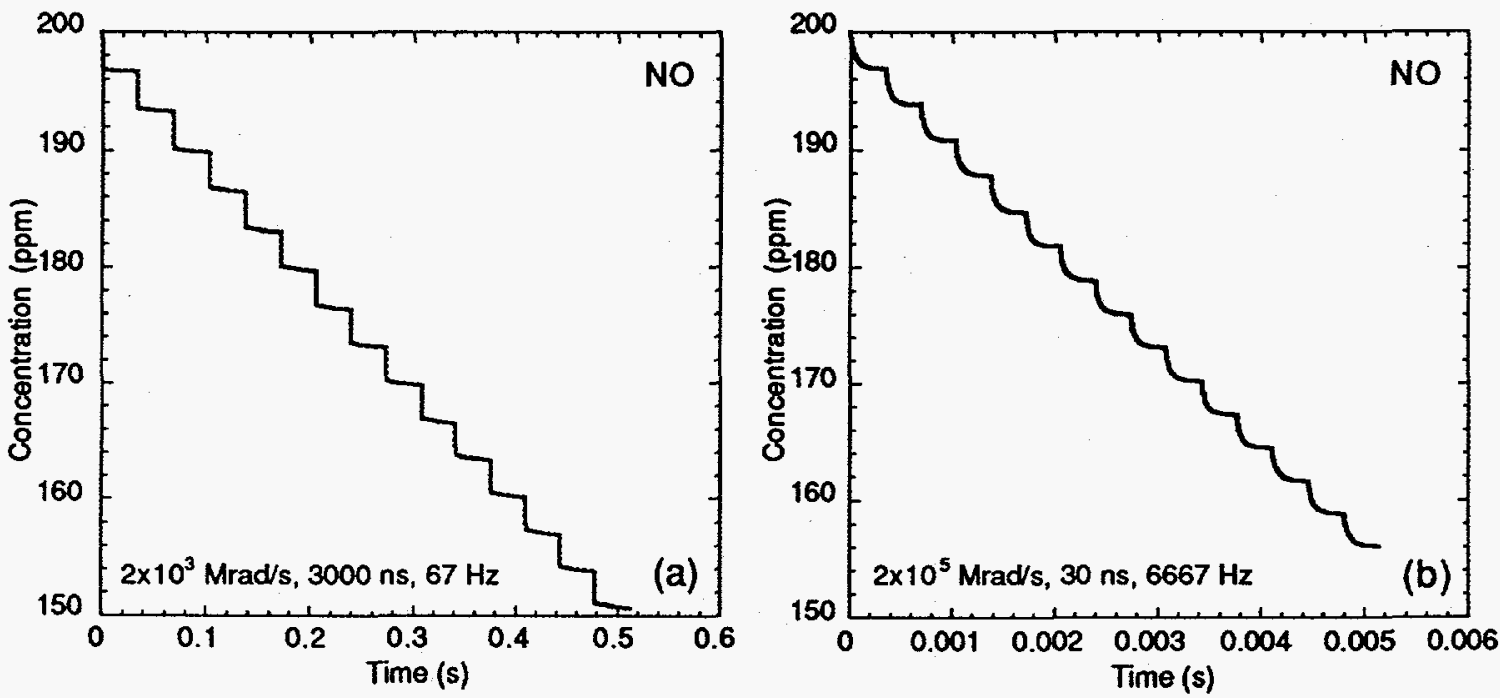

Figure 2. Evolution of the concentration of NO during the first 15 pulses of electron beam. 
$?$

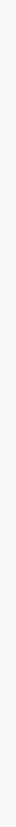





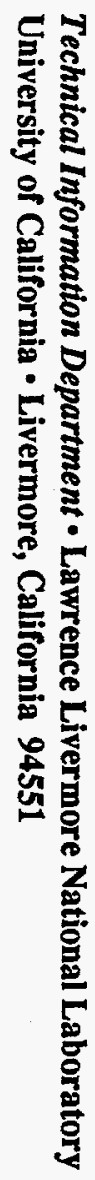

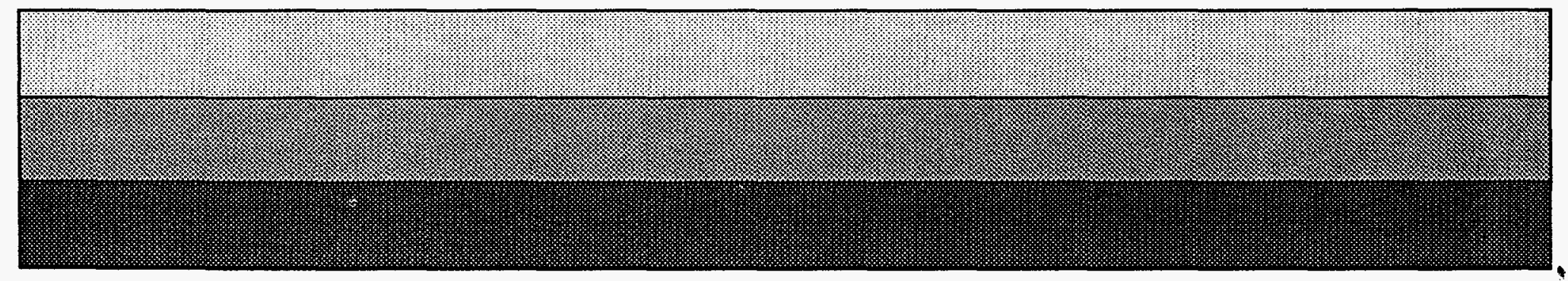

